\title{
How family firms execute open innovation strategies: \\ The Loccioni case
}

\section{Elena Casprini*}

Scuola Superiore Sant'Anna, 33 Piazza Martiri della Libertà, Pisa, 56127, Italy.

E-mail: e.casprini@santannapisa.it

\section{Alfredo De Massis}

Free University of Bozen- Bolzano, Piazza Università 1, Bolzano, 39100, Italy E-mail: $\underline{\text { Alfredo.DeMassis@unibz.it }}$ and

Lancaster University, UK

\section{Alberto Di Minin}

Scuola Superiore Sant'Anna, 33 Piazza Martiri della Libertà, Pisa, 56127, Italy.

E-mail: a.diminin@santannapisa.it

\section{Federico Frattini}

Politecnico di Milano, 4/b Via Lambruschini, Milano, 20133 , Italy.

E-mail: federico.frattini@polimi.it

\section{Andrea Piccaluga}

Scuola Superiore Sant'Anna, 33 Piazza Martiri della Libertà, Pisa, 56127, Italy.

E-mail: a.piccaluga@santannapisa.it

* Corresponding author

\section{This is an authors' version.}

Please cite as: Casprini E., De Massis A., Di Minin A., Frattini F., Piccaluga A. (2017). How family firms execute open innovation strategies: The Loccioni case. Journal of Knowledge Management. Vol. 21 (6), pp. 1459-1485. DOI: https://doi.org/10.1108/JKM-11-2016-0515. 


\title{
How family firms execute open innovation strategies: The Loccioni case
}

\author{
Purpose - This paper aims to shed light on how family firms execute open innovation strategies \\ by managing internal and external knowledge flows.
}

Design/methodology/approach - First, through a comprehensive literature review, the paper identifies the barriers to the acquisition and transfer of knowledge in open innovation processes. Second, it presents and discusses the results of an exploratory case study on Loccioni, an Italian family firm providing high-tech measurement solutions, highlighting how this family firm managed to overcome the barriers in executing an open innovation strategy.

\begin{abstract}
Findings - The case study shows that Loccioni faced specific challenges in acquiring and transferring knowledge in its open innovation processes and developed two idiosyncratic capabilities - labelled imprinting and fraternization - that helped the firm overcome the barriers to knowledge acquisition and transfer. The analysis shows that these two capabilities are enabled by the distinctive goals and social capital characterizing family firms.
\end{abstract}

Originality/value - The paper creates a link between open innovation and family business research with an empirically grounded model illustrating how the idiosyncratic capabilities of a family firm help overcome the critical barriers to the acquisition and transfer of knowledge in executing an open innovation strategy.

Keywords: Open Innovation, Family Firm, Capabilities, Non-economic Goals, Social Capital

\section{Introduction}

How do family firms execute an Open Innovation (OI) strategy? In particular, during this execution phase, how do family firms manage internal and external knowledge flows? This paper explores these research questions through the illustrative case study of an Italian family firm. Knowledge management lies at the very core of OI, defined as "the use of purposive inflows and outflows of knowledge to accelerate internal innovation, and expand the markets for external use of innovation, respectively" (Chesbrough, 2006:1). Traditionally, researchers have focused on the importance of pursuing an OI strategy, stressing "why" acquiring external knowledge and transferring internal knowledge beyond the firm's boundaries are necessary to compete (Enkel et al., 2009). However, a well-defined strategy needs to be paired with successful execution to produce superior performance (Noble, 1999). Nonetheless, little is known about "how" an OI strategy is executed and, in particular, how the characteristics of a firm's governance system influence the way internal and external knowledge flows are managed during the execution phase. This is quite surprising when considering that authority structures, incentive systems, and accountability norms, which are the observable manifestations of a governance system, strongly influence strategy execution (Crittenden and Crittenden, 2008; Noble, 1999).

Recently, increasing evidence has accumulated showing that family firms differ from nonfamily firms with regard to innovation processes (Classen et al., 2014; De Massis et al., 2015; De Massis et al., 2016; Kotlar et al., 2013). According to this research stream, family firms are characterized by an "ability-willingness paradox" (De Massis et al., 2015), whereby their willingness to engage in innovation activities is lower than in nonfamily firms despite their greater ability to do so (Chrisman et al., 2015). This "ability-willingness paradox" in family firm innovation captures and synthesizes a number of conceptual and empirical arguments that have been used to portray, on the one hand, the unique resources of family firms that may lead to superior competitive advantage in innovation (Carney, 2005; Sirmon and Hitt, 2003) and, on 
the other hand, the reasons that family firms are less willing to innovate (such as risk aversion, non-economic goals and difficulty in sharing control with nonfamily members). Following these insights, scholars have started to unearth why some family firms - such as Alessi, Electrolux, Ferrero, Salewa, and many others - are able to resolve this paradox and excel in innovation (De Massis et al., 2015).

The paper contributes to this debate by focusing on a particular aspect that may explain differences in how family firms execute an innovation strategy. In particular, the focus is on how family firms manage knowledge flows in executing an open innovation strategy, overcoming barriers to the acquisition and transfer of knowledge via the development of idiosyncratic capabilities.

Although open innovation has attracted much interest in the last decade among innovation scholars (see, e.g., Dahlander and Gann, 2010; Huizingh, 2011), surprisingly little effort has been made to understand how family firms execute OI and, in particular, how they manage internal and external knowledge in this execution phase. Some fragmented contributions focus on specific aspects, such as external technology acquisition (Kotlar et al., 2013) and search breadth in innovation (Classen et al., 2012). These studies suggest that family firms tend to prefer using internal knowledge, thus adopting a more closed approach to innovation, unless specific knowledge management practices are adopted, such as the presence of intellectual property (IP) mechanisms (Kotlar et al., 2013). However, how family firms use internal and external knowledge in executing an OI strategy would seem to be an under-researched topic (Urbinati et al., 2017).

The focus on the execution of an OI strategy is particularly important if considering that existing research typically assumes that once a strategic decision is taken, execution will follow (Beer and Eisenstat, 2000; Crittenden and Crittenden, 2008). This is, however, not always the case, and little is known about how family firm decisions are made and the processes by which these decisions are implemented (Chrisman et al., 2016). In particular, the execution of innovation decisions in family firms has not received as much attention in scholarly inquiry, even if this issue may be very important to understand the heterogeneity of innovation performance in family firms (Chua et al., 2012). The limited understanding of how family firms execute their innovation strategies is thus an important gap in knowledge, especially in relation to open innovation.

In an attempt to fill this gap in understanding the execution of OI in family firms, this paper presents and discusses an exploratory case study (De Massis and Kotlar, 2014; Yin, 2003). The case study examines how a family firm that executes an OI strategy has overcome the barriers to acquiring and transferring internal and external knowledge flows. Formally stated, the research question is: How do family firms execute an open innovation strategy? Specifically, during the execution phase, how do family firms manage internal and external knowledge flows?

Drawing on the knowledge-based view of the firm (Grant, 1996) and dynamic capabilities literature (Teece, 2007; Teece et al., 1997), this paper bridges the gap by analyzing "how" a family firm has overcome some critical barriers to acquiring and transferring knowledge in its effort to execute an OI strategy. The case under study is Loccioni, an Italian family firm that offers measurement solutions to improve the quality of products and processes for the manufacturing and services industry. Loccioni operates in a wide range of sectors (from energy to transport) and is renowned both nationally and internationally as a very "open" company.

The paper is structured as follows. The next section provides a literature review, identifies the main barriers to acquiring and transferring knowledge in OI - two relevant aspects of knowledge management - and summarizes prior research on innovation in family firms. The third section illustrates the research design and methodology. Thereafter, the Loccioni case is described as 
an insightful example of a family firm that successfully executed an open innovation strategy, managing internal and external knowledge flows. The qualitative account unveils two main capabilities - imprinting and fraternization - that allowed the family firm to overcome the barriers to knowledge management in OI. The study offers qualitative evidence on each capability and describes the micro-level activities underlying these capabilities. The last section draws some conclusions and outlines directions for future research.

\section{Literature Review and Theoretical Framework}

This paper focuses on "how" an OI strategy is executed in family firms. According to Chrisman et al. (2016), execution refers to how a firm "identifies decisions that must be made and tasks that must be completed to resolve issues and problems; how to sets objectives; how and to whom decisions and tasks are assigned or delegated; in what sequence the decisions are made and actions taken; the accountabilities and deliverables demanded from organizational actors" (p. 720). This definition highlights that execution refers to management processes, particularly in relation to tasks and decisions. As the authors point out, a defined strategy can be executed in different ways, which implies the importance of strategy execution more than its definition to explain good or bad firm performance.

In the context of an OI strategy, execution refers to "how" internal and external knowledge flows are managed. In the following, existing research on open innovation and family firm innovation is reviewed by examining the key topics in these two literature streams that inform the present exploratory case study.

\subsection{Open innovation: barriers to the acquisition and transfer of knowledge}

OI scholars have long stressed that an OI strategy improves firm performance. Most research on $\mathrm{OI}$ is consistent in showing that in dynamic environments, the capabilities to explore and exploit internal and external knowledge (Lichtenthaler and Lichtenthaler, 2009) are crucial for innovation performance. OI is indeed "all about leveraging and exploiting knowledge generated inside and even outside the firm, to develop and exploit innovation opportunities" (Chiaroni et al., 2010). However, limited attention has been paid to understanding "how" an OI strategy is executed. This is surprising when considering that strategy execution is important to understand why some companies perform well when they adopt an OI strategy, while others do not. Firms often fail to execute an OI strategy due to the knowledge management barriers they face (Verbano et al., 2015). The literature review distinguishes between the barriers to the acquisition and transfer of internal and external knowledge (Grant, 1996; Enkel et al., 2009; Kim et al., 2016; Teece, 2007). Specifically, acquisition refers to enriching the firm's own knowledge base through external sources, such as suppliers and customers (Enkel et al., 2009). Transfer refers to transferring knowledge within the firm (Nonaka, 1994) and beyond the firm's boundaries (Enkel et al., 2009).

\subsubsection{Barriers to knowledge acquisition}

Extant research (e.g., De Araújo Burcharth et al., 2014; West and Bogers, 2013) shows that acquisition of external knowledge is often impeded by two main factors: (a) negative attitudes towards external knowledge, and (b) the inability to identify valuable external knowledge sources. Prior studies point to the existence of cultural attitudes, such as the not-invented-here (NIH) syndrome (Antons and Piller, 2015), which may prevent the acquisition of external knowledge, regardless of the objective value of the external input (Antons and Piller, 2015). For example, Husted et al. (2012) suggest that companies may hoard knowledge, reject external knowledge, and hold attitudes towards mistakes that influence actual knowledge-sharing 
behavior. This knowledge sharing hostility is often due to the desire to protect and retain power and/or control. A second factor preventing acquisition of external knowledge is the difficulty in valuing and assimilating knowledge. For example, Diaz-Diaz and Saà-Pérez (2014) note that acquiring external knowledge is highly dependent on the level of the firm's internal knowledge base. Recent evidence also suggests that the impact of individuals' use of external sources on their ideation performance is influenced by coordination problems, such as integrating knowledge from diverse domains, and approval costs from senior managers who have to agree on engaging with external partners (Salter et al., 2015).

\subsubsection{Barriers to knowledge transfer}

Extant research has shown that "the central competitive dimension of what firms know how to do is to create and transfer knowledge efficiently within an organizational context" (Kogut and Zander, 1992:384). However, the OI paradigm has also emphasized the importance of transferring knowledge beyond the firm's boundaries (Enkel et al., 2009). Hence, knowledge transfer may occur within and beyond the firm's boundaries. Knowledge transfer deriving from internal and external sources is however a complex task (De Araújo Burcharth et al., 2014; Goh, 2002; Nonaka, 1994; Yih-Tong and Scott, 2005) since individuals may lack the trust needed to share knowledge (Holste and Fields, 2010) and managers' cognitive biases and mental models may lead to a wrong selection of projects (Wu et al. 2016). Knowledge transfer is particularly tricky when organizations have to share knowledge with external third parties. It is unsurprising then that firms often suffer from the so-called not-sold-here syndrome, i.e., resistance to sell knowledge and technology to external parties. This attitude originates from the fear of losing potentially useful knowledge in the long run (Savitskaya et al., 2010) or strengthening competitors (Lichtenthaler, 2011). Consequently, firms often avoid exploiting their internal knowledge (Huizingh, 2011).

\subsubsection{Solutions}

Prior research has shown that problems of knowledge acquisition and transfer may be overcome by changing the norms, expectations, working routines, and job functions in an organization (Salter et al., 2014); introducing ad hoc reward systems and formal practices (see, for example, Di Minin et al., 2010); employing appropriate rules and directives, routines, and group problem solving practices (Ardito and Messeni Petruzzelli, 2017; Grant, 1996); developing an organizational design with effective governance mechanisms, incentives, and controls (Wallin and Von Krogh, 2010). For example, among factors influencing the transfer of tacit knowledge within a firm, Joia and Lemos (2010) identify personal characteristics (e.g., mutual trust and common language), strategic approaches to knowledge management (e.g., type of training, recognition, and reward) and organizational structures (networks, power, and hierarchy). Other scholars note that developing absorptive capacity (Cohen and Levinthal, 1990; Zahra and George, 2002) allows overcoming specific barriers, particularly the inability to identify and value external knowledge sources. More recent studies suggest that individual, network and organizational factors (Dahlander et al., 2016; Salter et al. 2015) have an impact on the successful use of external source breadth. For example, Dahlander et al. (2016) argue that individuals need to allocate their attention to sources of knowledge and two individual approaches are viable to succeed in innovative search. In particular, they note that either a local approach, i.e. when individuals dedicate attention to the internal network, or a cosmopolitan approach, i.e. when individuals dedicate attention to a broad network of external partners, lead to innovative outcomes. However, to the authors' best knowledge, no studies explore the solutions implemented to acquire and transfer knowledge when family firms execute an OI strategy. 


\section{2 (Open) innovation in family firms}

Innovation in family firms has only recently attracted scholarly interest, as evidenced by the De Massis (2015) and De Massis et al. (2013) review articles examining the effect of the distinctive characteristics of family firms on innovation. Different definitions of family firms exist (Carney, 2005; Chua et al., 1999) and the present study defines a family firm as an enterprise where the family has the discretion to influence the firm's vision and the intention to transfer the business across generations (De Massis et al., 2012).

With regard to innovation in family firms, two main research streams can be identified. On the one hand, drawing on the resource-based view (RBV) and agency theory, scholars show that in pursuing innovation, family firms may rely on unique resources, such as familiness (Pearson et al., 2008; Carnes and Ireland, 2013), tradition (De Massis et al., 2016), social capital (Habbershon and Williams, 1999), and benefit from the alignment of incentives between owners and managers, thereby reducing agency costs and encouraging fast decision making (Craig and Dibrell, 2006). As such, family firms may leverage their unique characteristics to innovate. On the other hand, grounding their arguments in behavioral theory, other researchers argue that in the attempt to pursue non-economic utilities - whose accumulation leads to socioemotional wealth (Chrisman and Patel, 2012; Gómez-Mejía et al., 2007; Miller et al., 2015) family firms are more risk averse, less inclined to share control with non-family members, and more parsimonious (Carney, 2005). Thus, they tend to invest less in innovation (Sciascia et al., 2015), rely to a lesser extent on external sources of knowledge for technological collaborations (Jesus Nieto et al., 2015; Kotlar et al., 2013), and less inclined to adopt discontinuous technologies (Konig et al., 2013). Due to non-economic goals and the preservation of the family's socio-emotional wealth, family and non-family firms differ in their inclination to innovate (Gómez-Mejía et al., 2013). For example, the introduction of innovation may alter the status quo, thus hampering family authority and control over the innovation processes. As Gómez-Mejía et al. (2007) note, family firms may be both risk willing and risk adverse, depending on whether decisions are taken to avoid the loss of socioemotional wealth. Hence, the evidence is mixed. Gómez-Mejía et al. (2013) recently introduced an interesting perspective noting that family firms differ in decisions, such as R\&D investments, depending on whether these decisions create socioemotional wealth gains or losses.

In an attempt to organize existing views on the influence of family governance on innovation, some recent studies suggest that family firms are characterized by an "ability-willingness paradox" in innovation (Chrisman et al., 2015; De Massis et al., 2015). Accordingly, family firms are less willing to engage in innovation activities, although they have a greater ability to do so compared to nonfamily firms. An initial body of research on open innovation has recently stressed that although family firms do not have the same "inclination to engage in open innovation in comparison with nonfamily firms [...], they are thought to have superior ability in identifying opportunities and acquiring knowledge from outside their boundaries because of their non-economic goals" (Chrisman et al., 2015:312). However, scant attention has been paid to identifying the capabilities that allow family firms to overcome the barriers to acquire and transfer internal and external knowledge when executing an open innovation strategy. This lack of focus on implementation is particularly unfortunate because existing research typically assumes that once an innovation strategy is defined, execution will follow (Beer and Eisenstat, 2000). This is, however, not always the case, and little is known about how family firm decisions are made and the processes by which these are implemented (Chrisman et al., 2016). The execution of innovation decisions in family firms has not received as much attention in scholarly inquiry, even though it is an important issue to account for the heterogeneity of family firm performance in innovation (Chua et al., 2012). Some exceptions include Carnes and Ireland (2013) who conceptualize a relationship between family goals, resources, and resourcebundling processes to explain firm strategic decisions on innovation. De Massis et al. (2016) 
show that family firms can use different organizational designs to implement their innovation programs, with different implications on innovation performance. In sum, there is limited understanding of how family firms implement their innovation decisions and, to the authors' best knowledge, no research has thus far been conducted to understand the decisions, practices, and processes associated with managing the knowledge flows through which family firms execute OI strategies.

In an attempt to start bridging this gap, this study explores how a family firm has overcome the barriers to acquire and transfer knowledge in OI by leveraging its idiosyncratic capabilities.

\section{Research design}

The aim of this study is to illustrate how a family firm can manage knowledge flows in executing OI. Due to the novelty of the topic and given this study's research question, the authors conducted an in-depth exploratory case study (Yin, 2003). This method is particularly suited to answering "how" questions (Yin, 2003), and appears appropriate to gain in-depth understanding of how management processes unfold in family firms and how family governance shapes processes, such as executing open innovation (De Massis and Kotlar, 2014; Fletcher et al., 2016).

\subsection{Research setting}

The case study firm is Loccioni, a family firm based in Angeli di Rosora, a small village in the Marche region in Central Italy. This family firm was selected for four main reasons. First, the firm can be considered an insightful example of a family firm where the effect of family governance at work is particularly visible (De Massis et al., 2012). Indeed, Enrico Loccioni and his son Claudio Loccioni and daughter Maria Cristina Loccioni are actively involved in the firm and have the managerial discretion needed to influence the business vision. The firm is $100 \%$ owned by the family and all members work in the firm. Specifically, Enrico Loccioni is President, Claudio Loccioni is Director of one of the business units, and Maria Cristina Loccioni works in the accounting department. Before she passed away, Enrico Loccioni's wife, Graziella, also worked in the firm as head of the accounting department. Moreover, the business is clearly run with the intention of handing it over to the next generation. Second, the firm is very well known for its excellence in innovation, as evidenced by a number of prestigious awards, such as the National Award for Innovation (2010). Third, the firm is well known for making extensive use of open innovation (Baraldi et al., 2011; Del Baldo, 2012; Di Minin et al., 2016; Varvelli and Varvelli, 2014), and explicitly identifies itself as an "open company". Finally, the authors had easy access to data and information on the family firm as they have developed good relationships with the firm and the family over more than five years through past and ongoing collaborations on a number of research projects centered on open innovation. Thus, this case was chosen as it offers a distinctive and extraordinary setting to observe the phenomenon under investigation and considerable access to the firm was granted.

\subsection{Data collection}

Information was collected through 31 direct interviews, triangulated with other sources of data (Gibbert et al., 2008), such as the analysis of archival documentation, project reports, participation in meetings held at the company on innovation issues, and direct observation during four days spent in the family firm. These four days of observation enriched the development of documentation, the identification of workplace behavior, and other particular details (Locke, 2011). Specifically, this allowed the researchers to rely on a discovery-oriented interpretive approach and to emphasize an "insider" perspective (Salvato and Corbetta, 2013). 
The interviews were conducted face-to-face and lasted between 30 and 90 minutes. Three authors jointly conducted 14 interviews, while the remaining interviews were conducted by the first author. The interviews were recorded and transcribed, and focused on the firm's innovation process and the role of the family in decision making. The data collection followed three steps. Data on the firm's open innovation processes were collected in multiple stages between May 2012 and March 2017. In particular, formal interviews were conducted in three waves (May 2012-March 2013, May-October 2015, and February-March 2017), while informal talks and meetings took place during the four years. These data allowed the authors to identify the barriers to knowledge management in OI and how the family was able to overcome these. During the third round of interviews in March 2017, the research team conducted five additional interviews. In particular, to enrich understanding of the case, the authors interviewed a new employee who had joined the family firm six months previously. This allowed gaining insights from a newly hired person, thus providing further evidence on the role of the family from a new employee's perspective. A list of the interviewees' roles is provided in Appendix I. Regarding the interview protocol, the first questions related to the informant's general background (e.g., name, position, experience), followed by questions on the innovation process (e.g., what are the firm's main sources of ideas? How do you exchange knowledge with your colleagues? What are the challenges in managing knowledge?) and the role of the family in this process (e.g., what is the role of Enrico Loccioni and his family in [a specific topic that emerged during the interview]?). Questions on the role of the family were mainly linked to examples that emerged during the interviews (Kvale, 1996). The interview protocol was thus very broad, while digging deeply into the specific aspects that emerged during the interviews. Family members were also asked how they perceive their role within the firm.

\subsection{Data analysis}

Data were analyzed through an inductive approach (Gioia et al., 2013). Using the NVivo10 software to organize the material, an open coding procedure was followed making recourse to in vivo codes and listing the first-order concepts linked to the informants' meaning systems. The first and the third authors individually conducted an analysis of the interviews to identify the key emerging themes, discussed these themes, and agreed on representative labels. Thereafter, the authors undertook a second-order analysis to identify the deeper patterns in the data, leading to the second order themes, and iterated between theoretical abstractions related to family firm and OI research and the descriptive concepts. An example is the "inventor syndrome" theme. From the analysis of quotations and the identification of first-order concepts, it emerged that the informants directly mentioned the term "inventor syndrome", pointing out that this challenge concerns the overcapacity to develop new ideas and the need to select only one/some of these. Consequently, the authors searched open innovation literature to establish whether the "inventor syndrome" theme has previously been addressed and found only themes such as the not-invented-here and the not-sold-here syndromes. Thus, the informants described something new that warranted an ad hoc definition.

This iterative process between theory and evidence led to identifying some distinctive barriers to knowledge acquisition and transfer in family firms, as well as two family firm capabilities, their constituent second-order themes, and first order concepts. The findings are presented and discussed in detail in the next section. Figures 2 and 3 summarize the procedure followed, which shows the first-order categories, second-order themes, and aggregate theoretical dimensions.

\section{Findings}

This section presents the study's findings. Section 4.1 introduces an overview of Loccioni. Section 4.2 describes open innovation in Loccioni. Section 4.3 illustrates the barriers 
encountered by the family firm in implementing knowledge management while executing open innovation. Section 4.4 presents the family firm's two distinctive capabilities. Finally, Section 4.5 discusses the relevance of the firm's capabilities in overcoming the knowledge management barriers.

\subsection{Setting the scene: Loccioni}

Established in 1968, Loccioni is a family firm renowned worldwide as a high-tech solution provider of tailored quality-testing systems in several sectors, from healthcare to energy. Today the company has almost 400 employees (50\% with a university degree, $7 \%$ with a Ph.D.), an annual turnover of $€ 70$ million, and three international branches in China, Germany and the United States.

Loccioni's strategy has always focused on three main pillars: strong attention to people, central role of the territory, and the importance of co-developing processes with customers. Since its founding, Enrico Loccioni, founder and current owner, has employed an entrepreneurial model based on knowledge development and people's professional growth, recognizing the territory and its actors as the main engine of the firm's development, creativity and competitiveness. The international branches were established in recent years to remain closer to their end customers.

The family firm's mission is to "integrate ideas, people, and technologies to transform data into values". To pursue its mission, Loccioni has organized itself around five main business units (BU), namely, Industry, Energy, Environment, Mobility and Human Care, each with its own R\&D, and two emerging units, Train and Transport, and Electronics. All the BUs have measurement as their general core competence, but each has a specific set of capabilities in a specific field. Moreover, a cross-functional unit, SUMMA, created in 1992, aims to build transversal competencies in different fields. Specifically, six functions can be distinguished in SUMMA (People, Marketing, Production, Logistics, Administration, and Research for Innovation). Research for Innovation (RforI) consists of a group of 15 researchers tasked with exploring new technical fields and participating in European projects. Since 2014, the company also has a Business Innovation function, currently consisting of 6 people, created with the vision to develop new businesses. The firm invests $5 \%$ of revenues in R\&D.

All family members are employed in the firm, but non-family members also serve on the top management team (TMT). In particular, the TMT consists of Enrico Loccioni, founder and owner, his son Claudio Loccioni, engineer, who joined the family firm in 2004 and created he Human Care division, Gino Romiti and Renzo Libenzi who are, respectively, Innovation Director and the General Manager of SUMMA, Cristina Cristalli, bioengineer, who has worked at Loccioni since 1998 and is head of Research for Innovation, Tommaso Puerini, engineer, who entered Loccioni as a project manager in 2003, then became a key account manager between 2005 and 2008, and today is head of Business Innovation. Figure 1 presents the Loccioni family tree and the TMT. 


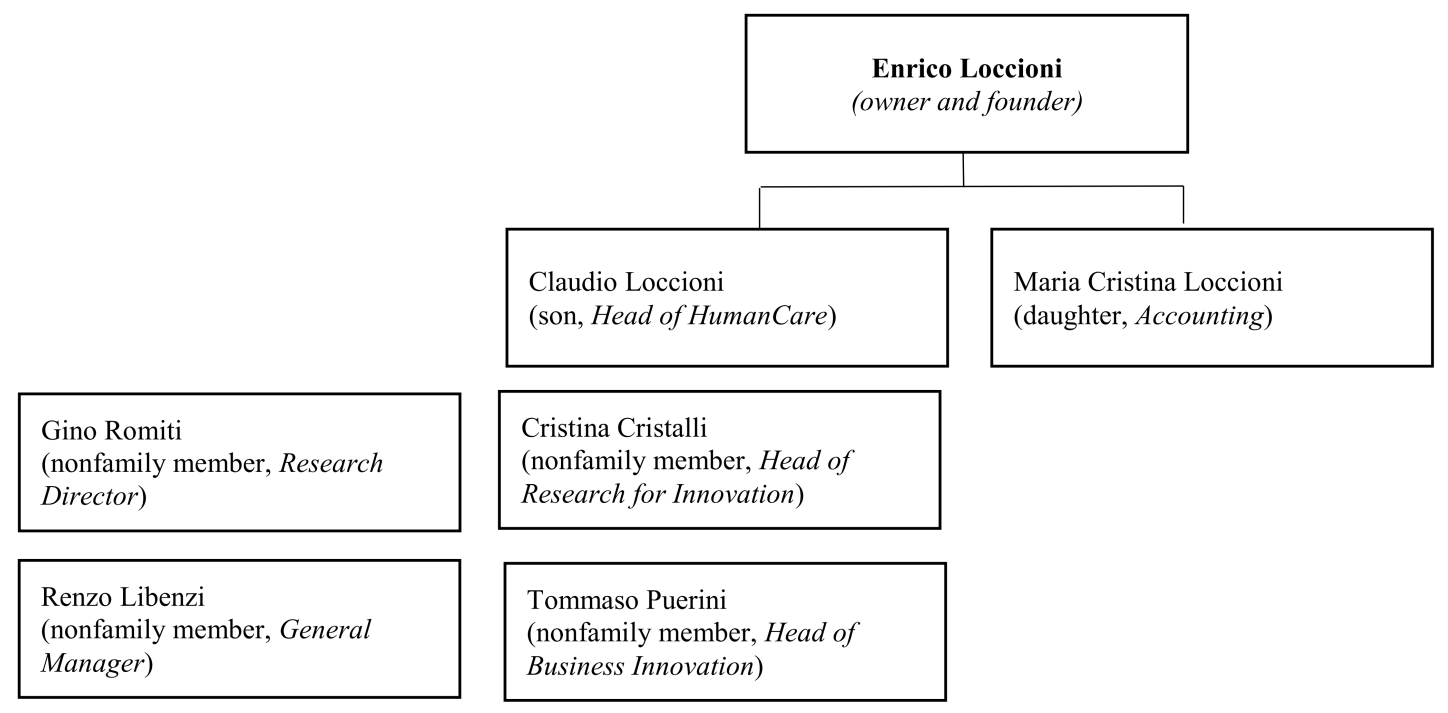

Figure 1. The Loccioni family tree and the Top Management Team

\subsection{Open Innovation in Loccioni}

This section begins by describing the role of the founder, Enrico Loccioni. The founder and his family have been crucial in shaping and infusing the values of the firm and setting the longterm direction. The family has always paid particular attention to change and innovation. Since Enrico Loccioni founded the firm, the firm has grown spurred by four main values: Energy, Imagination, Responsibility and Tradinnovation. These values are strongly and consistently promoted in the founder's and managers' speeches, in memos, websites, and press releases. Energy refers to the passion and motivation at the base of any "knowledge company" (another label often used by Loccioni to define itself). Imagination refers to the ability to look forward: according to Enrico Loccioni, this requires looking beyond what is currently being seen to create the future (as an example, see the video on The $2 \mathrm{KM}$ of Future ${ }^{1}$ ). Responsibility is about acting based on the awareness that everything that is done now has a consequence on the future. Finally, Tradinnovation stresses the importance of linking tradition in terms of the rural culture and experiences that characterize each local context to innovation. The Loccioni website (www.loccioni.com) states:

"We are an open company; open to young people and to long experienced ones, to customers, suppliers, competitors, to the scientific and public community. Openness nourishes the continuous longing for depth, new knowledge, will to change, innovation. Openness enhances the creation of new businesses, the development of new technologies, facilitating relations and the creation of international excellence networks, with whom to design future markets and technology applications."

Loccioni's OI capacity can be understood in terms of number of new ventures created ( 80 spinoffs), patents owned (in 2015, 24 patent families), and an impressive number of collaborations with 21 universities, 7 research and technological centers as well as educational institutions and retired collaborators.

The following section analyses how the family firm has overcome some of the critical barriers to knowledge acquisition and transfer in executing its open innovation strategy. The analysis reveals that the family firm faced specific barriers to managing knowledge flows and leveraged

${ }^{1}$ https://www.youtube.com/watch?v=rPheOHDl1EM (in Italian) 
its idiosyncratic characteristics (linked to the concepts of non-economic goals and social capital) to develop two distinctive capabilities that allowed overcoming these barriers. Figures 2 and 3 report the data structure, while some representative quotations from the case are presented in Appendix II.

\subsection{Barriers to knowledge management in the implementation of open innovation}

The barriers to the management of knowledge flows that Loccioni faced in executing its OI strategy are described next. Loccioni has dedicated substantial attention to all aspects linked to the implementation of OI. The firm is extremely sophisticated in its choice of knowledge sources and partners, and is very demanding in terms of knowledge transfer beyond the firm's boundaries. Starting from the data structure reported in Figure 2, the authors examine in detail the barriers to knowledge acquisition and integration that emerged from the case.

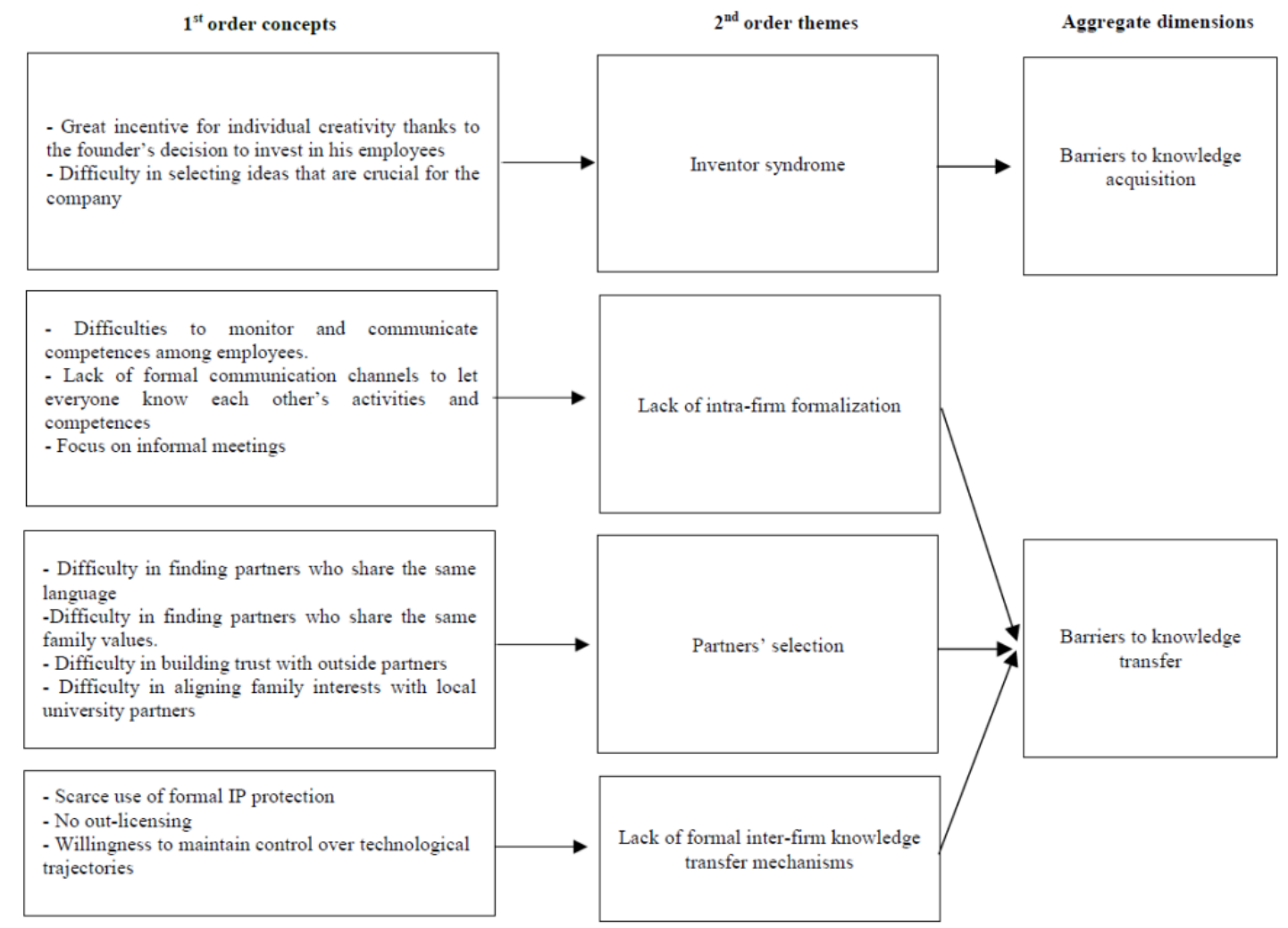

Figure 2. Data structure: barriers to knowledge acquisition and transfer

\subsubsection{Barriers to knowledge acquisition: the inventor syndrome}

With regard to the main barriers to knowledge acquisition, previous research has stressed the relevance of two barriers: the not-invented-here syndrome (NIH) and the difficulty in valuing and assimilating external knowledge. Instead, the evidence in this study suggests that a greater barrier to external knowledge acquisition for Loccioni is the so-called "inventor syndrome". The "inventor syndrome" refers to the overcapacity to internally develop new ideas and acquire external ideas, paired with the difficulty in selecting which ideas should be pursued. According to the interviews, Loccioni's employees have a widespread attitude to come up with new ideas deriving from the fact that the family has always invested in individual creativity, organizing several training programs and seminars. For example, the family firm organizes 7,000 hours of training per year. These investments have fostered an organizational climate that supports individual creativity. However, during the interviews, both the TMT and employees recognized 
the need to select the knowledge to acquire and the ideas/problems to focus on. As one of the interviewees stated:

"We need to be economically sustainable, we need to create value. [...] We need to understand if there is business beyond."

Consequently, according to Enrico Loccioni, it is important to focus on those ideas that are valuable for the firm. An example is the experience of one interviewee who mentioned several projects pursued with local high schools. In this case, the firm leaves the schools as much freedom as possible in developing their ideas and projects, and then selects what is actually important for the future of the family firm.

"It is the number that counts. Among the huge quantity of ideas and projects that arrive at our firm, there is always something that creates value."

\subsubsection{Barriers to knowledge transfer: lack of intra-firm formalization, partners' selection and inter-firm knowledge transfer mechanisms}

Loccioni has faced challenges with respect to knowledge transfer on two levels: within the firm's boundaries and beyond the firm's boundaries.

As regards knowledge transfer within the firm's boundaries (i.e., intra-firm), the qualitative account revealed one main difficulty, i.e., a lack of intra-firm formalization in transferring knowledge. The firm has faced challenges in establishing formal knowledge transfer rules and procedures within its boundaries, in particular, difficulties in monitoring and communicating competences among employees. As the informants noted during the interviews, in the past, when the firm was still an SME, the lack of rules and procedures was not a problem as the family firm was small enough and every employee knew what everyone else was doing. However, the same informants recognize that as the firm's size increased, the same rules and procedures gradually became a constraint. The interviews reveal that the main barrier to knowledge sharing has been the lack of formal communication channels to inform each about the activities and competences of others. Management is extremely aware of the relevance of formal knowledge sharing channels. The interviews also suggest that there are high expectations of the development of formalization channels, such as those that RforI ${ }^{2}$ plans to achieve. As one of the nonfamily managers said:

"Even the peacocks that are in our garden need to know what Research for Innovation (Rforl) is doing... Otherwise, I risk losing opportunities when I go to the client."

The lack of intra-firm formalization of knowledge transfer mechanisms is seen as particularly crucial for RforI, which has always been involved in EU projects. When these projects are concluded, in the absence of a proactive exploitation strategy, the results of such projects risk remaining on the shelves. During the interviews, the managers indicated that in the past the firm has missed exploitation opportunities and one of the informants acknowledged that more could be done in terms of cross-fertilizing the technologies developed.

On the other side, transferring knowledge beyond the firm's boundaries (i.e., inter-firm) is particularly challenging. First, Loccioni is highly demanding in selecting partners, looking for those that not only share the same language and values, but are also culturally aligned. As Cristina Cristalli noted:

\footnotetext{
${ }^{2}$ Research for Innovation (RforI) was created for long-term R\&D and is dedicated to the development of future technologies and the exploration of new fields of research. For this reason, RforI mainly collaborates with universities and research centers.
} 
"It is difficult to find the right person to collaborate with. Not a lot of people appreciate open innovation."

Moreover, according to the informants, local universities are not always able to provide an appropriate learning program. This forces the firm to look for distant partners. As one of the top managers stated, it is not always easy to align interests with local university partners:

"The firm is growing at a very fast pace, it is diversifying its areas of expertise and often the Marche region alone does not provide an adequate learning offering. The firm is then forced to look for talents across its regional boundaries."

Second, there is a lack of formal knowledge transfer mechanisms beyond the firm's boundaries. Specifically, there is scarce use of formal IP protection and the firm does not license out its technologies. Claudio Loccioni recurrently stated that the family firm does not like to use licensing-out as an approach to outbound OI. Traditionally, the IP management strategy in Loccioni is driven exclusively by the family's desire to maintain control over its technological trajectories. In OI terms, the fear of losing control over the technology trajectory is known as the "not-sold-here" syndrome (Lichtenthaler et al., 2010). The firm is the assignee of 24 patents families that protect technologies considered critical for the future of the business and does not seek formal IP protection for technologies that are not deemed essential. This attitude towards patenting partly explains why the firm does not license out its technologies.

\subsection{Capabilities in Loccioni}

The case study also reveals two firm-level capabilities that Loccioni has developed over time, here labelled "imprinting" and "fraternization". The development of these two capabilities is strictly related to Loccioni's nature as a family firm. Starting from the data structure reported in Figure 3, the next section describes these capabilities in detail. 


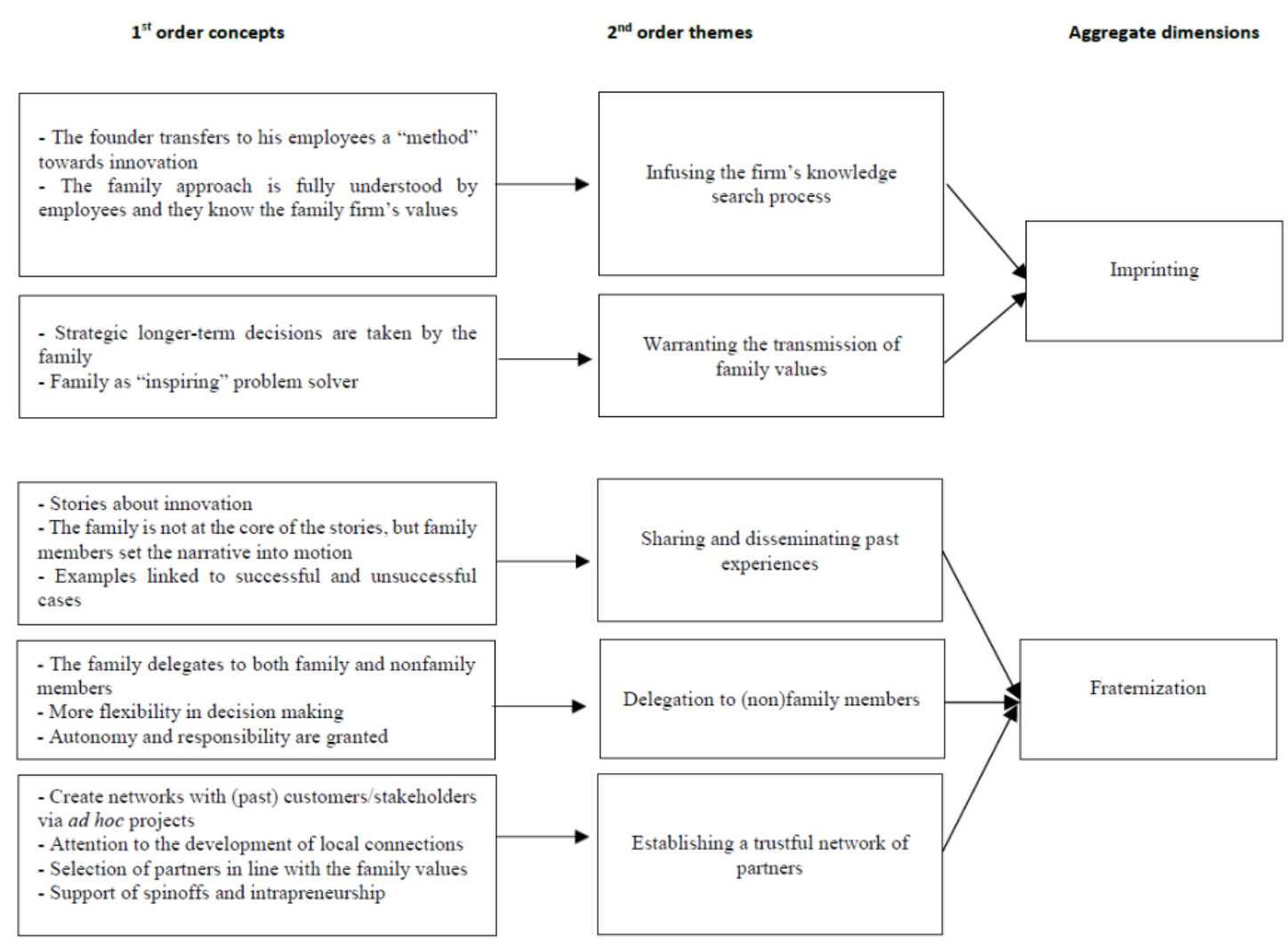

Figure 3. Data structure: capabilities

\subsubsection{Imprinting}

The first capability that emerged from the evidence is labelled "imprinting" and refers to the family firm's capability to bringing the founding family's values and approach to knowledge search and innovation culturally close to employees. Imprinting allows the family approach to be fully understood and reduces the risk of low integration of knowledge flows due to rejection or lack of understanding of family values, cultural gaps, and ineffective information transfer from the family to the business circle. Emerging from the data is that this search and innovation approach is driven by Enrico Loccioni and his family's non-economic goals; seeking profits and increasing the financial wealth of the family has never been their main goal. Rather, the firm's founder wanted to foster an environment with people who share and pursue his family values. As Enrico Loccioni stated:

"The reason for doing business is to build something that lasts over time. We want to leave [the world] to the new generations better than we have found it."

These family values are infused into every aspect of the family firm and conveyed to every member. As one young interviewee who spent her internship at Loccioni noted:

"During my first day, I received a lot of books about Loccioni. Moreover, a young lady from the "People" department introduced me to the family values and showed me all the facilities and the stories behind them. Since the first day, I could perceive the great importance Loccioni gives to the family firm's cultural and emotional aspects."

In terms of external knowledge acquisition, Enrico Loccioni's imprinting is evident in the firm's knowledge search process whereby he transfers to his employees a "method" towards innovation. This method consists of three elements. First, the company must look for customers 
that are number one on the market; it is no coincidence that the firm's customers include multinationals such as Samsung and Bosch. Second, people should pay attention to local resources as a source of innovation. Third, each individual should consider the firm as a social good. The firm is in fact responsible for local development and has a role in society. This is in line with the fact that, according to Enrico Loccioni, money and personal profit should not be the drivers of the firm's activities. As one of the interviewees noted, the company wants to make 'profit', but in its Latin meaning:

"The word profit comes from the Latin verb pro-facere that means in order to continue to do'. Consequently, for us, profit means creating wealth for future generations, and we reinvest this wealth in the firm in such a way that the firm continues to pursue its activities. This profit is reinvested in the territory in order to make the world better."

According to the informants, the family has the role of "warrantor" in transmitting these values. Enrico Loccioni and his family are always involved in the firm and committed to all critical issues. This is evident when considering that the family makes strategic longer-term decisions, thus maintaining control over the firm's technological trajectory. These decisions are taken with the help of the TMT. Put differently, the "not-sold-here" syndrome prevails for all technologies that are considered "distinctive" (Di Minin et al., 2010; Prahalad and Hamel, 1990). Moreover, the family is always present within the firm and remains committed to solving critical issues when they arise. The family does not act as a "coercive" problem solver, but rather an "inspiring" problem-solver. One of the informants noted that employees make decisions not because a family member says they must (coercively) do something, but because the family member serves as the trigger for a new, deeper, and more conscious decision-making process.

The family presence within the firm facilitates the dissemination of the founders' values. The family is the guarantee of the transmission of values. Tommaso Puerini, Head of Business Innovation, clarifies:

"The family guarantees the method, the approach, the culture. Within the next 50 years, clients will change, technologies will change, competences will change. However, our approach, our culture, our values and the Loccioni "method" towards innovation must not change."

\subsubsection{Fraternization}

Our case evidence reveals a second capability that Loccioni has developed labelled "fraternization". This refers to the firm's capability to develop stable and long-term relationships with employees and outside partners by devoting continuous attention to capitalizing on existing relationships and building trust in social interactions, both within and beyond the firm. While the imprinting capability derives from the non-economic goals that drive and inspire family firm behavior, fraternization results from the distinctive traits of the family's and the family firm's social capital.

Loccioni has built this capability through three main processes. First, the firm has incentivized the diffusion of past experiences through developing innovation stories. Communicating past experiences eases the information flow by supporting the creation of innovation memories. Loccioni's managers strongly believe that storytelling not only creates a memory of innovation, but is also a tool to connect individuals. Although the family is not the main character of these stories, which all center around innovation, family members play a pivotal role in disseminating these. More precisely, at the core of the stories are the experiences of individuals with innovation. Innovation is not only about new products, new business models or materials, but 
also about the organization, narrating what has worked and what has not. As an example, one of the employees noted:

"When I arrived, I noticed that the firm cares a lot about stories. Often people have told me to talk with one person rather than another since he/she has had direct experience and this could help me. Past episodes bring us what the family firm has done in the past and suggest the main pillars we should care about."

Reinforcing this statement, the founder observed that it is important to have an "archive of experiences":

"Innovation without an archive is not innovation. A percentage of the things that we are doing have already been done. But we need to be curious. Consequently, the archive represents the basis for searching things that have been done in the past, in different contexts. The principles are always the same."

Recently, the firm introduced what they call "pillole serali" [evening pills]. On average once a week for 30-45 minutes, employees are invited to listen to colleagues who share their experiences and knowledge about a specific topic, which may be technology-, corporate- or market-related.

Second, a key mechanism in developing internal relationships is delegation. To better coordinate the various activities of the firm, Enrico Loccioni and his family use delegation mechanisms (e.g., through empowering practices) for both family and nonfamily members. For example, all business units have a nonfamily manager (with the exception of Healthcare run by Claudio Loccioni). Delegation allows the firm more flexible and faster decision-making, and is linked to autonomy and responsibility. A key nonfamily informant noted:

"Everyone is free to choose and say what he/she thinks, but simultaneously we have a lot of responsibilities."

Consequently, each individual has autonomy and takes responsibility for what he/she is doing. As one of the family members noted:

"Individuals must be left free to pursue what they think is the best option to pursue."

In this context, the family has the role of "controller", but without being invasive. Moreover, delegation mainly concerns operational decisions. Strategic decisions, as emphasized by the control mechanisms, are taken by the family and the TMT, particularly with regard to very long-term strategic decisions.

"There is governance that lasts a life! There is a 'continuity' of approach. This is the biggest guarantee of a family firm. As an example we can cite the Flumen project. The family has decided to secure the Esino river. This river, statistically, floods every 100-150 years, the ROI will be seen in the next 100-150 years. I cannot image any manager making such kind of investment, except the family.'

Third, Enrico Loccioni has established long term relationships with several partners. First, Loccioni supports entrepreneurial activities within the firm. Enrico Loccioni has, for example, supported over 80 startup firms founded by employees. For the family firm, these spinoffs are a means of transferring the family firm's culture beyond its boundaries. As emerged during the interviews, these firms share the family's values and led to developing trustful relationships between Loccioni and external partners. Loccioni has developed over time a network of past customers and stakeholders and pays significant attention to maintaining this network alive and treating each member of the network as if they were part of the family. There is significant attention to the development of local connections driven by the founding family's attachment to the territory. Enrico Loccioni is aware of the family firm's role as connector (broker) in the network of excellence. As Enrico Loccioni noted: 
"We need to work with the best, with number one companies, first in the territory [...] and then in the world... But we make them feel part of the family."

As one of the nonfamily interviewees observed:

"I would like to tell you about my first meeting with Enrico Loccioni. He asked me why I was there and why I decided to go there, my story and background. Finally, he told me that everything that is carried out within the firm aims at improving the wellbeing of people and the environment. This requires effort and a very accurate selection of partners, but allows Loccioni to start long term collaborations and achieve sustainable and non-economic growth."

\subsection{How do the family firm capabilities help overcome knowledge management barriers?}

To help make sense of the various concepts and their relationships in the data, the authors constructed Figure 4, which summarizes the findings and illustrates how these two distinctive capabilities of family firms prove useful to overcoming knowledge management barriers in executing an open innovation strategy. As Figure 4 illustrates, imprinting is particularly crucial to overcoming barriers in the acquisition of knowledge, whereas fraternization is especially helpful in overcoming barriers in the transfer of knowledge.

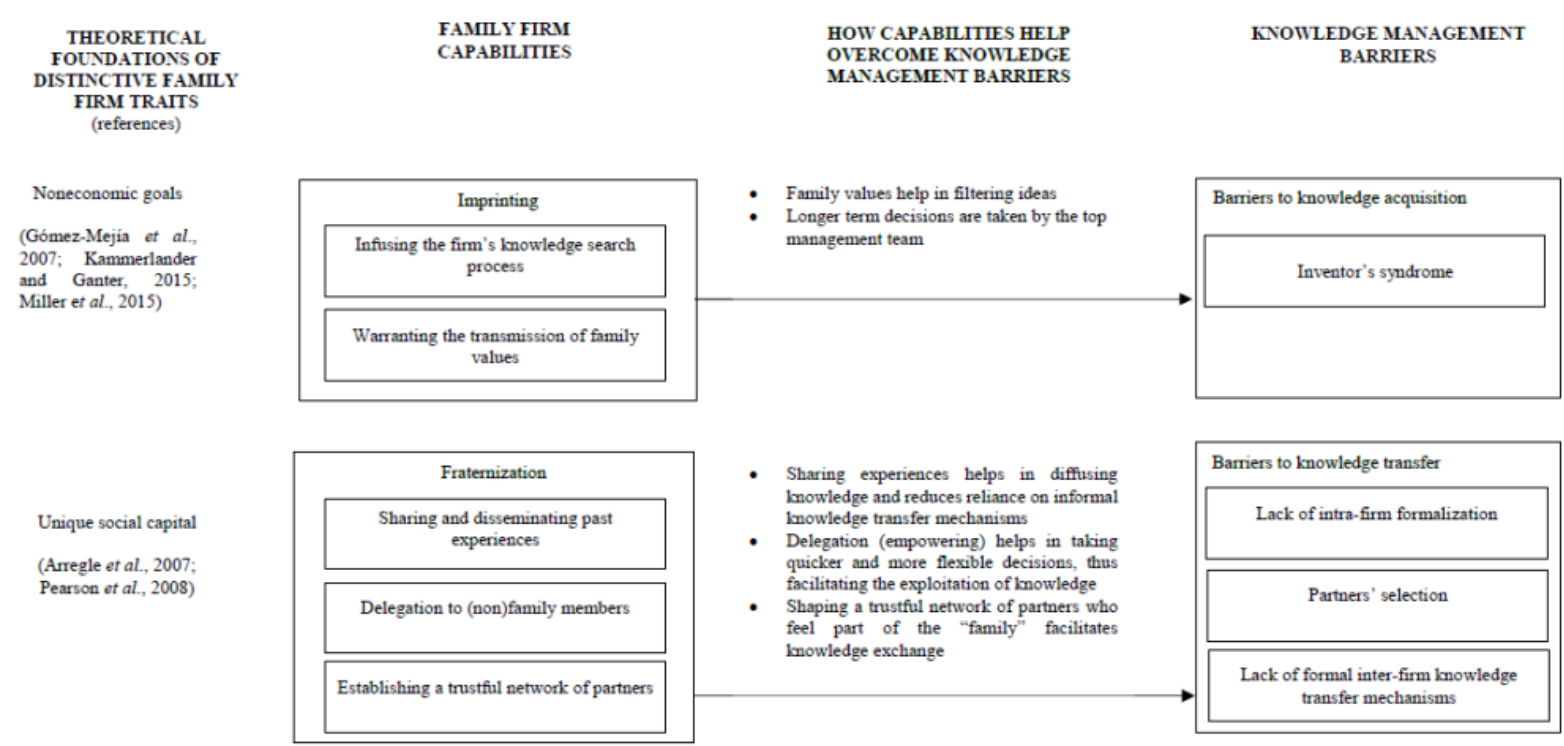

Figure 4. A model of how family firms overcome knowledge management barriers in executing an open innovation strategy

The imprinting capability helps surmount the inventor syndrome, which refers to the overcapacity in developing new ideas internally, acquiring ideas externally, and the difficulty in selecting which ideas to pursue. This imprinting capability helps managers and employees conquer knowledge acquisition barriers via two main mechanisms.

First, family values help filter ideas. The interviews highlight that all Loccioni employees are familiar with the founder's and his family's core values, while the managers share these same values. The interviewees noted that the family values of energy, imagination, responsibility, and tradinnovation are deeply embedded in their minds. The founder and the TMT continuously disclose these values, also in press releases and other forms of corporate communication. As one of the nonfamily interviewees pointed out: 
"One reason why managers share the same family values relies on the fact that they have actively participated in the creation and diffusion of the values."

Managers know how to distinguish the ideas that are in line with the family firm's values from those that are not. In particular, tradinnovation acts as a filter of ideas and has a central role in guiding Loccioni's selection processes and which projects to focus on. A recent example is Bosch. As one of the interviewees stated:

"Yesterday, we began a project with Bosch. We had alternatives available. But we have chosen Bosch. Bosch is a customer that completely represents what we mean by tradinnovation: it exists since 130 years, has a huge corporate culture, still embeds the entrepreneurial soul with respect to both technological values and the corporate environment. [...] Tradinnovation has led us to work with this customer. Tradition and innovation are two aspects that together ensure continuity for us."

By following the family firm's imprinting, managers are led by two drivers when searching for and selecting ideas. First, they tend to adopt a local search process, i.e., preferring local sources of knowledge when such knowledge is locally available. An example is the Leaf Community, a project that Loccioni has developed since 2008. For this project, the family firm relies on local partners and sources of knowledge and then involves other big players sharing the firm's attention to quality and respect for the environment. Leaf House is one of the building blocks of this project. This is a smart-house linking domotics with traditional, local building regulations (e.g., energy efficiency and waste minimization) and principles (i.e., energy and water autonomy). The informants noted that in developing Leaf House they looked for trustful partners who could espouse the value of creating something with no impact on the environment as well as offering the most comfortable solutions for end customers. Moreover, managers evaluate whether the ideas are valuable (in the long term) for the family firm by asking: (i) Does this idea allow the family firm to develop? (ii) Is the pursuit of this idea in line with the family's values and Loccioni's mission? Loccioni aims to develop competences and technologies that can provide social benefits to the territory. As one of the interviewees stated:

"The idea is to develop technology here, with small companies that help us. We prefer to be proactive rather than reactive, to create a local filière, to stimulate it. We do not want to become a production site, but to remain a knowledge-based company that socially contributes to the development of its territory."

In another informant's words:

"Values do not provide a solution. But values help in finding the solution. The family does not take operative decisions, but gives you the tools to make decisions."

Second, longer-term decisions on which ideas should be pursued are taken by the TMT. In particular, the family and the TMT, which is dominated by family members, are committed to selecting the technologies and projects to pursue in the long run. In other words, whereas shortterm decisions are taken at the single business unit level, strategic longer-term decisions are always taken by TMT, and consequently the family members. However, this does not prevent employees from sharing their ideas with the TMT and the family. Rather, they know that their ideas will be evaluated by the most experienced people in the firm in light of the family's values. As the TMT choses the future scope of business activities, the ideas chosen are in line with the family firm's longer-term, non-economic goals. Consequently, the family 'controls' and intervenes (with the TMT) on strategic longer-term decisions, while granting high autonomy for shorter-term decisions.

With regard to knowledge transfer, the family firm relies on its fraternization capability. Concerning the focus on knowledge transfer within the firm's boundaries, several managers stated that the founder and the family incentivize sharing experiences through elaborating 
innovation stories. These stories help transfer knowledge within the firm, allowing people to share experiences, values, perspectives, and outcomes, as well as helping to monitor and communicate past projects and competences among employees. Moreover, these stories have increased the sense of identity and attachment to the firm. To a certain extent, the diffusion of such stories has allowed individuals within the organization to reduce reliance on informal meetings as the main opportunity for internal knowledge sharing. All employees communicate and promote what they have done. As one of the nonfamily managers noted:

"The social capital, the trustful relationships of Loccioni are important for the creation of new businesses. Indeed, it can happen that useful contacts for that specific new business are already in the firm thanks to another older business unit. The fact that Loccioni is active in different fields and sectors facilitates the growth and consolidation of such a big network... We all feel part of a big family."

Second, the delegation mechanisms facilitate the transfer of knowledge both within and outside the firm. The interplay between imprinting and delegation allows managers to make decisions autonomously that are in line with the values imprinted by the founding family. Thanks to delegation, managers are able to make timely decisions on how to transfer projects within the firm's boundaries. Delegation and the ensuing empowering mechanisms are essential for operational decisions. Moreover, empowered managers can directly deal with external partners without requiring the family's approval. Delegation also enhances the sense of attachment to the family firm, thus nurturing a strong sense of trust.

Third, the development of a trustworthy ecosystem of partners facilitates knowledge exchange. First, incentivizing entrepreneurial activities (i.e., starting up new businesses) ensures that knowledge is better exploited. According to many informants, Loccioni has been able to orchestrate the resources of the territory, creating an ecosystem consisting of spin-offs and a network of local and distant partners that share the family's values. Enrico Loccioni stated that one of his main goals is to spur the entrepreneurial activities of his employees (what he calls "family intrapreneurship"). As an illustrative example, an interviewee mentioned that a few years ago, Loccioni developed a technology to evaluate the structural integrity of GPL tanks. At a certain point, the firm decided that this market was not crucial to the development of core competences and decided to abandon the business. However, due to their individual passion and entrepreneurial spirit, two of Loccioni's employees decided to create their own company based on this technology. Today, this company has over 50 employees and is a growing business. Loccioni not only supported this spinoff, but is particularly proud of it and this company has now become a trustful partner.

Thus, the firm's reliance on its strong social capital has facilitated the development of a trustworthy network of partners. The selection of partners is crucial for managers, as Cristina Cristalli noted:

\section{"The firm can count on several long-term relationships developed over time and pays considerable attention to fostering networks of past employees, customers and partners."}

Some of the interviewed managers stressed the importance of the network of projects such as SilverZone (network of retired partners who share their knowledge and experience), the Nexus project (network of local enterprises), the BlueZone and U-Net projects (two projects intended to involve high school students and universities respectively). Knowledge transfer is easier and quicker within the networks that the firm has nurtured over time, where every member feels part of the "family": all parties share the same language and values. As Claudio Loccioni noted, knowledge transfer occurs through traditional mechanisms based on a handshake and experience, "we trust each other and do not need to sign contracts". Supporting the creation of 
spinoffs is an assurance for the founding family that these new ventures will be inspired and driven by values and goals that are similar to the family's. As Claudio Loccioni stated:

"It is a sort of certification of experience. Whether that person will continue to work with us or not, he will probably set up a lab that will be similar to our labs, he will probably look for similar suppliers and in any case his behavior will be inspired by our family values."

This is a particular aspect of Loccioni: individuals with the ambition to start their own business have an extraordinary tutor - the family founder - and the family as a whole is willing to share its experiences, while the firm assures its support in the spinoff's early years.

Moreover, managers recognize that knowledge may be transferred in different ways than formal IP protection. In particular, Loccioni pursues an open service innovation strategy and codevelopment with its customers. This allows the firm to rely more on trust, rather than on formal IP implementation. For example, Lab@AOR is a public-private partnership for innovation in healthcare between Ancona University Hospital and the HealthCare BU with the aim of innovating technologies, processes, buildings, and empowering people. Since 2007 (when the project was launched), the aim of Lab@AOR is to develop a comprehensive approach to innovation in healthcare. In this context, the firm has relied on trust and long-term relationships with local partners rather than on the formalization of a strict IP regime. Another example is the KITE Lab (Knowledge Intensive Testing Environment). The KITE Lab has been created by Loccioni in 2016 in order to conduct test campaigns (including component characterization, advanced benchmarking of products and challenging measurements for product development) and develop innovation with and for its clients.

\section{Discussion and conclusion}

The Loccioni case study offers some insights into the family firm's distinctive capabilities that allowed it to overcome the barriers to knowledge acquisition and transfer in executing an OI strategy. These distinctive capabilities, labelled imprinting and fraternization, are theoretically rooted in two distinctive family firm traits, namely, the existence of non-economic goals (Gómez-Mejía et al., 2007; Kammerlander and Ganter, 2015; Kotlar and De Massis, 2013; Miller, et al., 2015) and their unique social capital (Arregle et al., 2007; Pearson et al., 2008; Yli-Renko et al., 2001).

The study illustrates how the family firm's imprinting helps overcome the inventor syndrome, which emerges as a distinctive barrier to knowledge acquisition in family firms. This barrier relates to innovation processes overall, regardless of their open or closed nature. However, this syndrome is particularly exacerbated in those firms embracing open innovation, since they will likely face the complexity of managing both internal and external knowledge flows. The case evidence reveals that the imprinting capability is linked to the concept of socioemotional wealth (Miller et al., 2015; Gómez-Mejía et al., 2007). Miller et al. (2015) note that several noneconomic goals drive a controlling family's behavior, such as considerations of community contribution, family reputation, social status, nurturing parochial family desires, and creating an evergreen organization for the new generation. Here, the non-economic goals are linked to preserving and improving the territory, innovating in respect of tradition, and creating an evergreen organization characterized by a strong identity shaped by the controlling family. In particular, Enrico Loccioni aims for a positive impact on the surrounding territory and innovating responsibly. In so doing, the firm recognizes traditions and local resources as sources of knowledge as well as the importance of external stakeholders.

The term "imprinting" refers to the "conditions at the time of an organization's founding" (Boeker, 1989:492). According to strategic management literature, the conditions at the time of 
foundation affect the way firms react, changing their strategic choices, or remaining inert and preserving their strategy when facing environmental changes (Boeker, 1989). The founder's vision and values (Garcì-Alvarez and Lòpez-Sintas, 2001) are imprinted in and adopted by the second generation. This assures a sense of "stable" change and long-term strategic criteria (Hsu and Chang, 2011). The founder's values help identify the knowledge to acquire, the problems to solve, the ideas to focus on. The case illustrates that imprinting, i.e., the capability to bring the founding family's values and approach to knowledge search and innovation culturally close to employees, is driven by the controlling family's non-economic goals, and these distinctive goals direct the firm's behavior in filtering ideas, selecting longer-term ideas, and shaping the search process, thus helping the firm overcome the "inventor syndrome".

A second key finding derives from fraternization, i.e., the capability to develop stable and longterm relationships with employees and outside partners, by devoting continuous attention to capitalizing on existing relationships and building trust in social interactions.

The term fraternization derives from the Latin word frater (i.e., brother) and refers to turning someone who does not belong to the family into a brother, implying a family-like association with nonfamily members. This capability is enacted by the family firm's unique bundle of social capital. Family firms provide a unique context to create strong social capital constituted by the firms' network ties, shared vision and language, trust, norms, obligations, and identification. These resources lead to easier information access and greater associability (Pearson et al., 2008). Social capital increases trust and consequently facilitates knowledge transfer mechanisms, both within and between the firm's boundaries. Social capital is recognized as an important resource for family firms (Pearson et al., 2008; Sirmon and Hitt, 2003).

This case study illustrates three ways to facilitate knowledge transfer. First, exchanging internal knowledge and experiences (via shared stories); in this respect, the findings add to Kammerlander et al.'s (2015) study on how founder or family stories affect innovation in family firms.

Second, knowledge transfer is facilitated by delegation mechanisms rendering the firm more flexible and quicker in dealing with the dynamic markets it competes in. Moreover, the coexistence of family members over two generations and (non)family members in the TMT enables the firm to simultaneously maintain strong family values and a professionalized management team capable of mobilizing and coordinating the firm's internal and external resources.

Third, the firm has carefully created a trustful network with external partners and relies on unconventional and informal knowledge transfer mechanisms. This allows the firm to create an environment characterized by trust and long-term relationships where every member of the network feels part of the family. Social capital is a crucial resource for knowledge management (Yli-Renko et al., 2001) and facilitates sharing and using tacit knowledge (Holste and Fields, 2010). The firm highly relies on its own tacit knowledge (Nonaka, 1994) and on the strong relationships it has formed over the years with past collaborators and partners. Trust and longerterm relationships help the firm select partners that are in line with the family's vision and values, and create a common language among them. The network of partners is already familiar with Loccioni's culture and modus operandi. Moreover, the case suggests that a family firm can transfer knowledge in less conventional ways. Family firms are developing new forms of appropriation and knowledge transfer. In this case, deploying competitive advantages in unique forms such as supporting spin-offs, family-stimulated entrepreneurial initiatives, and relying on co-development with partners rather than licensing out. This family firm has been able to create a new diffused model of knowledge transfer that does not reside in traditional knowledge protection mechanisms, but in new business models that span the firm's boundaries and enable the creation of ecosystems led by the family firm. 
In family firms, knowledge management requires a balance between the need to maintain control over technologies and exploit external and internally unused technologies. The first is guaranteed by the controlling role exercised by the family, while the second is enabled by delegation mechanisms. In particular, the imprinting (particularly the warranting the transmission of family values mechanism) and fraternization (particularly the delegation to nonfamily members mechanism) capabilities would seem to balance each other. On the one hand, the imprinting capability allows the family to maintain control and shape the firm's exploration processes. The family is present and provides guidance to overcome the inventor syndrome. On the other hand, the family's relational capability allows the firm to share knowledge within the firm's boundaries, make timely decisions through delegation mechanisms, and exploit knowledge through recourse to a trustworthy network of partners. Consequently, this case study illustrates the successful trade-off between maintaining core knowledge and exploiting it to take advantage of OI. This may shed light on the abilitywillingness paradox whereby family firms pursue non-economic goals (willingness) and simultaneously use delegation (ability) in implementing an OI strategy.

This paper integrates two research streams, i.e., open innovation and family firms, illustrating and exploring how a family firm may leverage its distinctive traits in acquiring and transferring knowledge during the execution of an open innovation strategy (Grant, 1996; Teece, 2007; Easterby-Smith and Prieto, 2008). This study extends previous research in a number of ways. First, it provides empirical evidence on the challenges entailed in executing an open innovation strategy in a family firm. By focusing on the execution phase, the paper attempts to bridge a gap in innovation research and particularly research on innovation in family firms, which stresses that an open innovation strategy is likely to improve firm performance, but underemphasizes how the execution of such a strategy can make the difference between success and failure. Second, the empirical evidence points to the existence of a barrier to knowledge acquisition in the family firm, i.e., the inventor syndrome, which existing open innovation research has thus far not explored (Lichtenthaler and Ernst, 2006; Verbano et al., 2015; Salter et al., 2014). Overcreativity represents a problem in closed innovation contexts and is exacerbated in open contexts. As Verganti (2016) and Verganti (2017) notes, managers need to capture the most promising opportunities in the overabundance of ideas. The case study illustrates that this barrier is particularly important in family firms and represents an important contribution to research on innovation and particularly family firm innovation. Third, the study highlights the existence of two distinctive capabilities in family firms that are helpful in overcoming barriers to knowledge acquisition and transfer, labelled imprinting and fraternization. The qualitative analysis suggests that these should be conceived as a particular subset of firm-level capabilities enacted by the distinctive resources and traits of family firms. As such, the exploratory evidence adds to the body of literature on the power or ability of family firms and the implications on innovation (e.g., De Massis et al., 2015) by exploring the organizational mechanisms that may help overcome the well-known "innovation paradox" in family firms. Fourth, the qualitative account illustrates how family firms execute OI strategies, thus advancing understanding of how the distinctive features of a governance archetype may affect innovation, and more precisely, strategy execution (Chrisman et al., 2015). Fifth, the study contributes to the growing body of research on the organizational implications of open innovation (see e.g., Bianchi et al., 2016) by focusing on the organizational mechanisms linked to knowledge transfer in open innovation processes that affect the successful implementation of an open innovation strategy.

As with all studies, this one suffers from some limitations which also provide opportunities for future research. First, owing to the nature of the research design, the findings cannot be statistically generalized without further empirical studies on the execution of OI strategies in family firms. The insights derive from evidence found in an illustrative and exploratory case study. Future research is needed to examine the boundary conditions of such insights. The paper 
suffers from the typical limitation of single case study research (Gibbert et al., 2008). As previous research shows, subjectivity due to the researchers' interpretation leads to three main problems of accuracy and face validity, discriminant validity, and consistency (Grant and Verona, 2015). Moreover, due to the heterogeneity of family firms (Chua et al., 2012), future research could adopt a multiple case study design (Eisenhardt and Graebner, 2007) involving different types of family firms. Second, the study focuses on family firm-level capabilities, without considering individual family-related capabilities. In particular, future research might investigate how incoming new generations influence knowledge management flows. Last, the barriers identified are not exclusively family firm-related barriers, but may also characterize nonfamily firms and future research should investigate how similar barriers are overcome in such firms.

The paper also offers some valuable managerial implications for family firm owners and managers. In particular, the study suggests that delegation helps family firms not only in reacting faster to technological change, but also in increasing their social capital and building relational trust. Delegation to nonfamily members is unusual in family firms, where owners tend to centralize authority rather than ceding power to nonfamily members (Carney, 2005). Family firm managers are hence encouraged to delegate more power to nonfamily members when their goals are in line with the controlling family's goals and intentions. Moreover, the case study analysis introduces an interesting example of a family firm that is impacting its institutional context (Wright et al., 2014), thus creating an ecosystem of actors who not only share knowledge, but are also influenced by the innovation method pursued by the family firm. This is particularly important in highly dynamic environments, where the capability of acquiring and transferring knowledge among partners may fasten the innovation process. The Loccioni case should hopefully clarify the relevance of this institutional perspective for innovation managers. Third, the paper points to the importance for family firms to clearly identify and diffuse their values, both within and beyond their organizational boundaries. Family firms with clearly defined values and able to share a common approach to innovation are likely to face smaller coordination problems and lower approval costs (e.g., costs incurred in the approval required for activating new partnerships)- two of the key factors that extant research has identified as critical for successfully implementing open innovation (Salter et al. 2014). Accordingly, owners are advised to purposefully infuse and nurture their values within the organization over time. Finally, owners and managers should be aware that knowledge might be diffused in unconventional ways, and new are the paths through which an organization can profit from it. Traditionally, formal IP protection has been considered as the preferred way to maintain control over technological trajectories. However, as the case study suggests, codevelopment and open service innovation might represent valuable alternatives to create, share and profit from new knowledge.

Implementing OI is extremely demanding and there is no easy way or fast track to it. However, the two distinctive capabilities emerged from this case study seem to "support the diffusion, sharing and transfer of knowledge within the firm and with the external environment" (Chiaroni et al., 2010:266), which are at the core of open innovation, showing that open innovation is possible even in the context of family firms.

\section{References}

Antons, D. and Piller, F. (2015), "Opening the Black Box of "Not Invented Here": Attitudes, Decision Biases, and Behavioral Consequences", The Academy of Management Perspectives, Vol. 29 No. 2, pp. 193-217. 
Ardito, L. and Messeni Petruzzelli, A. (2017), "Breadth of external knowledge sourcing and product innovation: the moderating role of strategic human resource practices", European Management Journal, Vol. 35 No. 2, pp. 261-272.

Arregle, J.-L., Hitt, M.A. and Sirmon, D.G. (2007), "The Development of Organizational Social Capital: Attributes of Family Firms”, Journal of Management, Vol. 44 No. 1, pp. 73-95.

Baraldi, E., Gregori, G.L. and Perna, A. (2011), "Network evolution and the embedding of complex technical solutions: the case of the Leaf House network", Industrial Marketing Management, Vol. 40 No.6, pp. 838-852.

Beer, M. and Eisenstat, R.A. (2000), "The silent killers of strategy implementation and learning”, Sloan Management Review, Vol. 41 No. 4, pp. 29-40.

Bianchi, M., Croce, A., Dell'Era, C, Di Benedetto, A. and Frattini, F. (2016), “Organizing for inbound open innovation: how external consultants and a dedicated R\&D unit influence product innovation performance", Journal of Product Innovation Management, Vol. 33 No. 4, pp. 492510.

Boeker, W. (1989), "Strategic change: the effects of founding and history", Academy of Management Journal, Vol. 32 No. 3, pp.489-515.

Carnes, C.M. and Ireland, R.D. (2013), "Familiness and Innovation: resource bundling as the missing link", Entrepreneurship Theory \& Practice, Vol. 37, pp. 1399-1420.

Carney, M. (2005), "Corporate governance and competitive advantage in family-controlled firms", Entrepreneurship Theory and Practice, Vol. 29 No. 3, pp.249-265.

Chesbrough, H. (2006), Open Innovation: Researching a New Paradigm, Oxford: Oxford University Press.

Chiaroni, D., Chiesa, V. and Frattini, F. (2010), "Unravelling the process from Closed to Open Innovation: evidence from mature, asset-intensive industries", $R \& D$ Management, Vol. 40 No. 3, pp. 222-245.

Chrisman, J.J. Chua, J.H., De Massis, A., Frattini, F. and Wright, M. (2015), "The ability and willingness paradox in family firm innovation", Journal of Product Innovation Management, Vol. 32 No. 3, pp. 310-318.

Chrisman, J.J., Chua, J.H., De Massis, A., Minola, M. and Vismara S. (2016), "Management Processes and Strategy execution in Family Firms: From 'What' to 'How", Small Business Economics, Vol. 47 No. 3, pp. 719-734.

Chrisman, J.J. and Patel, P.C. (2012), "Variations in R\&D investments of family and nonfamily firms: behavioral agency and myopic loss aversion perspectives", Academy of Management Journal, Vol. 55 No. 4, pp. 976-997.

Chua, J.H., Chrisman, J.J. and Sharma, P. (1999), "Defining the family business by behaviour", Entrepreneurship Theory \& Practice, Vol. 19, pp. 19-39.

Chua, J.H., Chrisman, J.J., Steier, L.P. and Rau, S.B. (2012), "Sources of Heterogeneity in Family Firms: an introduction", Entrepreneurship Theory \& Practice, Vol. 36, pp. 1103-1114.

Classen, N., Carree, M., van Gils, A. and Peters, B. (2014), "Innovation in family and nonfamily SMEs: an exploratory analysis”, Small Business Economics, Vol. 42, pp. 595-609.

Classen, N., Van Gils, A., Bammens, Y. and Carree, M. (2012), "The Search Breadth of Family SMEs”, Journal of Small Business Management, Vol. 50 No. 2, pp. 191-215.

Cohen, W.M. and Levinthal, D.A. (1990), “Absorptive capacity: a new perspective on learning and innovation”, Administrative Science Quarterly, Vol. 35, pp. 128-152. 
Craig, J. and Dibrell, C. (2006), “The Natural Environment, Innovation, and Firm Performance: A Comparative Study", Family Business Review, Vol. 19 No. 4, pp. 275-288.

Crittenden, V.L. and Crittenden, W.F. (2008), "Building a capable organization: the eight levers of strategy implementation”, Business Horizons, Vol. 51, pp. 301-309.

Dahlander, L. and Gann, D.M. (2010), "How open is innovation?", Research Policy, Vol. 39 No. 6, pp. 699-709.

Dahlander, L., O'Mahony, S., and Gann, D. M. (2016), "One foot in, one foot out: how does individuals' external search breadth affect innovation outcomes?", Strategic Management Journal Vol. 37 No. 2, pp. 280-302.

De Araújo Burcharth, A.L., Knudsen, M.P. and Sondergaard, H.A. (2014), "Neither invented nor shared here: the impact and management of attitudes for the adoption of open innovation practices", Technovation, Vol. 34 No.3, pp. 149-161.

De Massis, A. (2015), "Family Business and Innovation”, In D.B. Audretsch, C.S. Hayter, A.N. Link (Eds.), Concise Guide to Entrepreneurship, Technology and Innovation, Edward Elgar, Cheltenham.

De Massis, A., Chua, J.H. and Chrisman, J.J. (2012), "State of the art of family business research". In A. De Massis et al., eds. Family Business Studies. An Annotated Biography. Cheltenham, UK: Edward Elgar, pp. 10-46.

De Massis, A., Di Minin, A. and Frattini, F. (2015), "Family-driven innovation: resolving the ability and willingness paradox to unlock the innovation potential of family firms", California Management Review, Vol. 58 No. 1, pp. 5-19.

De Massis, A., Frattini, F., Kotlar, J., Messeni Petruzzelli, A. and Wright, M. (2016), "Innovation through tradition: lessons from innovative family businesses and directions for future research", Academy of Management Perspectives, Vol. 30 No. 1, pp. 93-116.

De Massis, A., Frattini, F. and Lichtenthaler, U. (2013), "Research on Technological Innovation in Family Firms: Present Debates and Future Directions", Family Business Review, Vol. 26 No. 1, pp. 10-31.

De Massis, A., Frattini, F. and Pizzurno, E. (2015), "Product innovation in family versus nonfamily firms: an exploratory analysis", Journal of Small Business Management, Vol. 53 No. 1, pp. 1-36.

De Massis, A. and Kotlar, J. (2014), "The case study method in family business research: Guidelines for qualitative scholarship", Journal of Family Business Strategy, Vol. 5 No. 1, pp. 15-29.

De Massis, A., Kotlar, J., Chua, J.H. and Chrisman, J.J. (2014), “Ability and willingness as sufficiency conditions for family-oriented particularistic behavior: implications for theory and empirical studies", Journal of Small Business Management, Vol. 52 No. 2, pp. 344-364.

De Massis, A., Kotlar, J., Frattini, F., Chrisman, J.J. and Nordqvist, M. (2016), "Family Governance at Work: Organizing for New Product Development in Family SMEs, Family Business Review, pp. 1-25.

De Massis A., Sharma P., Chua J.H., and Chrisman J.J. (2012), Family Business Studies: An Annotated Bibliography. Edward Elgar, Cheltenham Glos, UK.

Del Baldo, M. (2012), "Family and territory values for a sustainable entrepreneurship: the experience of Loccioni Group and Varnelli Distillery in Italy", Journal of Marketing Development and Competitiveness, Vol. 6 No. 3, pp. 120-139. 
Dìaz-Dìaz, N.L., and de Saà Pérez, P. (2014), "The interaction between external and internal knowledge sources: an open innovation view", Journal of Knowledge Management, Vol. 18 No.2, pp. 430-446.

Di Minin, A., De Marco, C.E., Marullo, C., Piccaluga, A., Casprini, E., Mahdad, M. and Paraboschi, A. (2016), Case Studies on Open Innovation in ICT. Institute for Prospective Technological Studies, Joint Research Centre. JRC Science for Policy Report; EUR 27911 EN; doi:10.2791/433370

Di Minin, A., Frattini, F. and Piccaluga, A. (2010), "Fiat: Open innovation in a downturn (19932003)”, California Management Review, Vol. 52 No. 3, pp. 132- 159.

Easterby-Smith, M. and Prieto, I.M. (2008), "Dynamic Capabilities and Knowledge Management: an Integrative Role for Learning?", British Journal of Management, Vol. 19, pp. 235-249.

Eisenhardt, K.M. and Graebner, M.E. (2007), "Theory Building from cases: opportunities and challenges”, Academy of Management Journal, Vol. 50 No.7, pp. 25-32.

Enkel, E., Gassmann, O. and Chesbrough, H. (2009), "Open R\&D and open innovation: exploring the phenomenon", $R \& D$ Management, Vol. 39 No. 4, pp. 311-316.

Fletcher, D., De Massis, A., and Nordqvist M. (2016), "Qualitative Research Practices and Family Business Scholarship: A Review and Future Research Agenda", Journal of Family Business Strategy, Vol. 7 No. 1, pp. 8-25.

Garcìa-Alvarez, E. and Lòpez-Sintas, J. (2001), "A taxonomy of founders based on values: the root of family business heterogeneity”, Family Business Review, Vol. 14 No. 3, pp. 209-230.

Gibbert, M., Ruigrok, W. and Wicki, B. (2008), "What passes as a rigorous case study?", Strategic Management Journal, Vol. 29, pp. 1465-1474.

Gioia, D.A., Corley, K.G. and Hamilton, A.L. (2013), "Seeking qualitative rigor in inductive research: notes on the Gioia Methodology", Organizational Research Methods, Vol. 16, pp. 15-31.

Goh, S.C. (2002), "Managing effective knowledge transfer: an integrative framework and some practical implications", Journal of Knowledge Management, Vol. 6 No.1, pp. 23-30.

Gómez-Mejía, L., Campbell, J.T., Martin, G., Hoskinsson, R.E., Makri, M. and Sirmon, D.G. (2013), "Socioemotional wealth as a mixed gamble: revisiting family firm R\&D investments with the behavioural agency model", Entrepreneurship Theory and Practice, Vol. 38, pp. 13511374 .

Gómez-Mejía, L.R., Haynes, K.T., Nunes-Nickel, M., Jacobson, K.J.L. and Moyano-Fuentes, J. (2007), "Socioemotional Wealth and business risks in family-controlled firms: evidence from Spanish olive oil mills", Administrative Science Quarterly, Vol. 52 No. 1, pp. 106-137.

Grant, R.M. (1996), "Toward a knowledge-based theory of the firm", Strategic Management Journal, Vol. 17, pp. 109-122.

Grant, R. M., and Verona, G. (2015), "What's holding back empirical research into organizational capabilities? Remedies for common problems", Strategic Organization, Vol. 13, pp. 61-74.

Habbershon, T.G. and Williams, M.L. (1999), "A Resource-Based Framework for Assessing the Strategic Advantages of Family Firms", Family Business Review, Vol. 12 No. 1, pp. 1-26.

Holste, J.S. and Fields, D. (2010), "Trust and tacit knowledge sharing and use", Journal of Knowledge Management, Vol. 14 No. 1, pp. 128-140. 
Hsu, L. C. and Chang, H.C. (2011), "The role of behavioural strategic controls in family firm innovation", Industry and Innovation, Vol. 18, pp. 709-727.

Huizingh, E.K.R.E. (2011), "Open innovation: State of the art and future perspectives", Technovation, Vol. 31 No. 1, pp. 2-9.

Husted, K., Michaiova, S., Minbaeva, D.B., and Pedersen, T. (2012), "Knowledge-sharing hostility and governance mechanisms: an empirical test", Journal of Knowledge Management, Vol. 16 No. 5, pp. 754-773.

Jesus Nieto, M., Santamaria, L. and Fernandez, Z. (2015), "Understanding the innovation behavior of family firms", Journal of Small Business Management, Vol. 53 No. 2, pp. 382-399.

Joia, L.A. and Lemos, B. (2010), "Relevant factors for tacit knowledge transfer within organisations”, Journal of Knowledge Management, Vol. 14 No. 3, pp. 410-427.

Kammerlander, N, Dessì, C., Bird, M., Floris, M. and Murru, A. (2015), “The Impact of Shared Stories on Family Firm Innovation: A Multicase Study", Family Business Review, Vol. 28 No. 4, pp. 1-23.

Kammerlander, N. and Ganter, M. (2015), "An Attention-Based View of Family Firm Adaptation to Discontinuous Technological Change: Exploring the Role of Family CEOs' Noneconomic Goals", Journal of Product Innovation Management, Vol. 32 No. 3, pp. 361-383.

Kim, B., Kim, E., \& Foss, N. J. (2016) "Balancing absorptive capacity and inbound open innovation for sustained innovative performance: An attention-based view", European Management Journal, Vol. 34 No. 1, pp. 80-90.

Kogut, B. and Zander, U. (1992), "Knowledge of the firm, combinative capabilities, and the replication of technology", Organization Science, Vol. 3 No. 3, pp. 383-397.

Konig, A., Kammerlander, N. and Enders, A. (2013), "The family innovator's dilemma: how family influence affects the adoption of discontinuous technologies by incumbent firms", Academy of Management Review, Vol. 38 No. 3, pp. 418-441.

Kotlar, J. and De Massis, A. (2013), "Goal Setting in Family Firms: Goal Diversity, Social Interactions, and Collective Commitment to Family-Centered Goals", Entrepreneurship Theory \& Practice, Vol. 37, No. 6, pp. 1263-1288.

Kotlar, J., De Massis, A., Frattini, F., Bianchi, M. and Fang, H. (2013), "Technology Acquisition in Family and Nonfamily Firms: A Longitudinal Analysis of Spanish Manufacturing Firms", Journal of Product Innovation Management, Vol. 30 No. 6, pp. 10731088.

Kvale, S. (1996), Interviews: An Introduction to Qualitative Research Interviewing, London: Sage.

Lichtenthaler, U. (2011), "Open Innovation: past research, current debates, and future directions", Academy of Management Perspectives, Vol. 25 No. 1, pp. 75-94.

Lichtenthaler, U. and Ernst, H. (2006), "Attitudes to externally organising knowledge management tasks: a review, reconsideration and extension of the NIH syndrome", $R \& D$ Management, Vol. 36 No. 4, pp. 367-386.

Lichtenthaler, U., Ernst, H. and Hoegl, M. (2010), "Not-sold-here: how attitudes influence external knowledge exploitation”, Organization Science, Vol. 21 No. 5, pp. 1054-1071.

Lichtenthaler, U. and Lichtenthaler, E. (2009), "A Capability-Based Framework for Open Innovation: Complementing Absorptive Capacity", Journal of Management Studies, Vol. 46 No. 8, pp. 1315-1338. 
Locke, K. (2011), "Field research practice in management and organization studies: reclaiming its tradition of discovery", The Academy of Management Annals, Vol. 5 No. 1, pp. 613-652.

Miller, D., Wright, M., Le Breton-Miller, I. and Scholes, L. (2015), "Resources and Innovation in Family Businesses: the Janus-face of socioemotional preferences", California Management Review, Vol. 58 No. 1, pp. 20-41.

Noble, C.H. (1999), "The eclectic roots of strategy implementation research", Journal of Business Research, Vol 45, pp. 119-134.

Nonaka, I. (1994), “A Dynamic Theory of Organizational Knowledge Creation”, Organization Science, Vol. 5 No.1, pp. 14-37.

Pearson, A.W., Carr, J.C. and Shaw, J.C. (2008), "Toward a Theory of Familiness : A Social Capital Perspective”, Entrepreneurship Theory \& Practice, Vol. 32 No. 6, pp. 949-970.

Prahalad, C. K., and Hamel, G. (1990), “The Core Competence of the Corporation”, Harvard Business Review, Vol. 68 No. 3, pp. 79-91.

Salter, A., Criscuolo, P. and Ter Wal, A.L.J. (2014), "Coping with Open Innovation: responding to the challenges of external engagement in R\&D", California Management Review, Vol. 56 No. 2, pp. 77-95.

Salter, A., Ter Wal, A. L. J., Criscuolo, P., and Alexy, O. (2015), "Open for Ideation: Individual-Level Openness and Idea Generation in R\&D", Journal of Product Innovation Management, Vol. 32 No.4, pp. 488-504.

Salvato, C. and Corbetta, G. (2013), "Transitional leadership of advisors as a facilitator of successors' leadership construction”, Family Business Review, Vol. 26 No. 3, pp. 235-255.

Savitskaya, I., Salmi, P. and Torkkeli, M. (2010), "Barriers to Open Innovation: Case China", Journal of Technology Management \& Innovation, Vol. 5 No. 4, pp. 11-21.

Sciascia S., Nordqvist M., Mazzola P., and De Massis A. (2015), "Family Ownership and R\&D Intensity in Small and Medium-Sized Firms", Journal of Product Innovation Management. Vol. 32, No. 3, pp. 349-360.

Sirmon, D.G. and Hitt, M.A. (2003), "Managing Resources: linking unique resources, management and wealth creation in family firms", Entrepreneurship Theory \& Practice, Vol. 27 No. 4 , pp. 339-359.

Teece, D.J. (2007), "Explicating dynamic capabilities: the nature and microfoundations of (sustainable) enterprise performance", Strategic Management Journal, Vol. 28 No. 13, pp. 1319-1350.

Teece, D.J., Pisano, G. and Shuen, A. (1997), "Dynamic capabilities and strategic management”, Strategic Management Journal, Vol. 18 No. 7, pp. 509-533.

Urbinati A., Franzò S., De Massis A., Frattini F. (2017). "Innovation in family firms: A review of prior studies and a framework for future research". In Brem A., Viardot E. (Eds.). Revolution of Innovation Management - Internationalization and Business Models, Palgrave MacMillan, Basingstoke, Hampshire, UK.

Varvelli, M. L. and Varvelli, R. (2014), 2KM di Futuro. L'impresa di Seminare Bellezza. Il Sole 24 Ore.

Verbano, C., Crema, M. and Venturini, K. (2015), "Innovation Profiles in Italian Small and Medium-sized Enterprises”, Journal of Small Business Management, Vol. 53 No. 4, pp. 10521075 . 
Verganti, R. (2017), Overcrowded. Designing Meaningful Products in a World Awash with Ideas, The MIT Press, Cambridge, MA.

Verganti, R. (2016), “The Innovative Power of criticism”, Harvard Business Review, Jan-Feb, pp. 89-95.

Wallin, M.W. and Von Krogh, G. (2010), "Organizing for Open Innovation: focus on the Integration of Knowledge”, Organizational Dynamics, Vol. 39 No. 2, pp. 145-154.

West, J. and Bogers, M. (2013), "Leveraging external sources of innovation: a review of research on open innovation", Journal of Product Innovation Management, Vol. 31 No. 4, pp. 814-831.

Wright, M., Chrisman, C., Chua, J.H. and Steir, L.P. (2014), "Family enterprise and context", Entrepreneurship Theory \& Practice, Vol. 38, pp. 1247-1260.

Wu, A. Y. H., Little, V. J., and Low, B. (2016), "Inbound open innovation for pharmaceutical markets: a case study of an anti-diabetic drug in-licensing decision", Journal of Business \& Industrial Marketing, Vol. 31 No. 2, pp. 205-218.

Yih-Tong, P., and Scott, S.J.L. (2005), “An investigation of barriers to knowledge transfer", Journal of Knowledge Management, Vol. 9 No. 2, pp. 75-90.

Yin, R.K. (2003), Case Study Research. Design and Methods, SAGE Publications, Thousand Oaks.

Yli-Renko, H., Autio, E. and Sapienza, H.J. (2001), "Social capital, Knowledge acquisition, and knowledge exploitation in young technology-based firms", Strategic Management Journal, Vol. 22 No. 6/7, pp. 587-613

Zahra, S.A. and George, G. (2002), "Absorptive capacity - a review, reconceptualisation and extension", Academy of Management Review, Vol. 27 No. 2, pp. 185-203. 


\section{APPENDIX I}

Table I. Interviewee roles

\begin{tabular}{|c|c|c|}
\hline Interviewee & Role & $\begin{array}{ll}\text { Number } & \text { of } \\
\text { interviews } & \\
\end{array}$ \\
\hline Enrico Loccioni & Founder and owner & 2 \\
\hline Claudio Loccioni & Enrico Loccioni's son and Head of HumanCare Business Unit & 2 \\
\hline Cristina Cristalli & Head of Research for Innovation & 2 \\
\hline Renzo Libenzi & General Manager & 1 \\
\hline Gino Romiti & Research Director & 1 \\
\hline Tommaso Puerini & Head of Business Innovation & 2 \\
\hline Damiano Loppi & Since 2005, Commercial Manager BU Energy & 1 \\
\hline Massimo Peretti & Since 2001, Sales Director - Mobility e Home & 1 \\
\hline Gilberto Polzoni & Since 2000, Software Engineer & 1 \\
\hline Marco Pacenti & Since 2001, Director - BU Home & 1 \\
\hline Luca Marassi & Director - BU Mobility & 1 \\
\hline Luca Lazzari & Since 2007, Director Marketing & 1 \\
\hline Gianluca Battistoni & Since 2008, Project Manager BU Home & 1 \\
\hline Maria Paola Palermi & Since 1996, Director - Communication & 1 \\
\hline Marinella Massacesi & Since 2008, Business Development Home/Energy & 1 \\
\hline Paolo Moscatelli & Since 2008, Business Development Environment & 1 \\
\hline Mirko Buraglioli & Production & 1 \\
\hline Alberto Basili & Administration & 1 \\
\hline Damiano Antonelli & Head of Production & 1 \\
\hline Alessandro De Grassi & R\&D - BU Automotive & 1 \\
\hline Daniele Possanzini & R\&D - BU Environment & 1 \\
\hline Giacomo Angione & Research for Innovation & 1 \\
\hline Riccardo Paci & Funding and Networking & 1 \\
\hline Simonetta Piangerelli & HR \& Communication & 1 \\
\hline Francois Colson & Key Account Manager - BU Automotive & 1 \\
\hline Noemi Ombrosi & Internship - Business Innovation & 2 \\
\hline
\end{tabular}

\section{APPENDIX II}

Table II. Representative quotations

\begin{tabular}{|c|c|}
\hline 2nd order theme & Representative quotations \\
\hline Inventor syndrome & $\begin{array}{l}\text { - "We can improve our capacity to filter projects. There should be a market" } \\
\text { - "In this company, ideas come from everywhere" } \\
\text { - External visits represents a source of ideas }\end{array}$ \\
\hline $\begin{array}{l}\text { Lack of } \\
\text { formalization }\end{array}$ & $\begin{array}{l}\text { - "Research for innovation is still isolated. We need communication in } \\
\text { - "Werstanding what it is doing" } \\
\text { "Weed a memory of innovation. This memory may also be helpful for other } \\
\text { - "We need to formalize meetings to exchange information" } \\
\text { - "Knowledge transfer procedures are informal" } \\
\text { - "We need a shared language and methods" }\end{array}$ \\
\hline Partners' selection & $\begin{array}{l}\text { - "Not many people appreciate open innovation. Therefore, it is difficult to find } \\
\text { the right person to collaborate with" } \\
\text { "Loccioni cooperates with a network of former employees, who are even } \\
\text { ambassadors of the Loccioni method, but this is still very limited" }\end{array}$ \\
\hline
\end{tabular}




\begin{tabular}{|c|c|}
\hline $\begin{array}{l}\text { Lack of formal inter-firm } \\
\text { knowledge } \quad \text { transfer } \\
\text { mechanisms }\end{array}$ & $\begin{array}{l}\text { - "When new technologies are developed, Loccioni does not want to sell them } \\
\text { to the customer" } \\
\text { "Few ideas are patented" } \\
\text { - "We patent those ideas that are important for customers. We protect ideas that } \\
\text { may also have multiple customers (e.g., we have patents for Apoteca)" }\end{array}$ \\
\hline $\begin{array}{l}\text { Warranting the values' } \\
\text { transmission }\end{array}$ & $\begin{array}{l}\text { - "Everyone wants to bring you [as family] into the decision process" } \\
\text { - "The family should understand in which decisions it should be involved in or } \\
\text { not.... But we are always committed... with people and with the selection of } \\
\text { people, with important customers or problems with important customers" } \\
\text { - "You wake up and you think about work. You go to sleep and you think about } \\
\text { work. This happens because you love your work" } \\
\text { "Before taking a decision, we share it within the family, but also within the } \\
\text { firm. This is because there are key shared values within the firm. These values } \\
\text { are clear within the family firm" } \\
\text { "There is a "listening to" culture. We listen to the needs of people. This culture } \\
\text { was introduced by my mother" }\end{array}$ \\
\hline $\begin{array}{l}\text { Infusing the firm's } \\
\text { knowledge search process }\end{array}$ & $\begin{array}{l}\text { - "The past is the "humus"" } \\
\text { - "Innovation has become a "method"" } \\
\text { - "The firm within the territory is not a private good, but a social good" } \\
\text { - Projects such as the Leaf Community and } 2 \mathrm{Km} \text { of Future represent examples } \\
\text { of the continuum between past and future" } \\
\text { "My role [Enrico Loccioni] is that of seeking, meeting, and looking around. } \\
\text { This is the choice that led me when I decided to become an entrepreneur. My } \\
\text { role should be a role that stimulates looking for new things" } \\
\text {-The role of the entrepreneur is also that of motivating and involving people } \\
\text { in developing long-term projects" } \\
\text { "Within this territory we can find culture, public, schools, people, families of } \\
\text { people... what we sustain is that, to realize such a kind of firm, we need a } \\
\text { territory: the territory is a value, and the culture of the territory is an extra } \\
\text { value. Hence we must act in such a way that the firm within a territory is not } \\
\text { only a private firm, but also becomes a social good" } \\
\text { "Knowledge resides in your closest colleagues and in the many people you } \\
\text { meet, but it is also embedded in the territory you live in and in its traditions" }\end{array}$ \\
\hline $\begin{array}{l}\text { Sharing and disseminating } \\
\text { past experiences }\end{array}$ & $\begin{array}{l}\text { - "Having a shared culture helps" } \\
\text { - "Storytelling is not about the family, but about successful and unsuccessful } \\
\text { cases" }\end{array}$ \\
\hline $\begin{array}{l}\text { Delegation to (non)family } \\
\text { members }\end{array}$ & $\begin{array}{l}\text { - "Today family and firm are managed separately. At the beginning, they were } \\
\text { one single thing. Today, they are still a single thing, but the family works in } \\
\text { the firm to manage the "box of values"" } \\
\text { " "The family has set a model with its own values" } \\
\text { - "[Delegation] has allowed us to grow [Worldwide] many small businesses are } \\
\text { born with one idea. They grow, but they slowly die because they do not } \\
\text { delegate" }\end{array}$ \\
\hline $\begin{array}{l}\text { Establishing a trustful } \\
\text { network of partners }\end{array}$ & $\begin{array}{l}\text { - "We do not do a lot of basic research. There are universities and research } \\
\text { centers that do this. The most important thing is to be able to integrate their } \\
\text { knowledge and to provide a solution to the market" } \\
\text { "A lot of co-development takes place with customers since in practicing } \\
\text { innovation you are never sure about the positive outcomes of your solutions" } \\
\text { - "We do R\&D with } 8 \text { or } 10 \text { strategic suppliers. [...] We go with them to the } \\
\text { customers. We customize the solutions with them. We pursue shared programs } \\
\text { for our HR" } \\
\text { "Usually Loccioni does not provide seed investments to these young } \\
\text { companies. It rather guarantees logistic support and cooperation to help them } \\
\text { grow even outside Loccioni" } \\
\text { "Loccioni is a stimulus for intrapreneurship" }\end{array}$ \\
\hline
\end{tabular}

